\title{
Consumer acceptance of circular business models
}

\author{
Remi Elzinga*, Denise Reike, Simona O. Negro, Wouter P.C. Boon \\ Utrecht University, Copernicus Institute of Sustainable Development, the Netherlands
}

\section{A R T I C L E I N F O}

\section{Article history:}

Received 22 June 2019

Received in revised form

15 November 2019

Accepted 3 January 2020

Available online 7 January 2020

Handling Editor: Bin Chen

\section{Keywords:}

Consumer behaviour

Consumer acceptance

Circular business models

Theory of planned behaviour

Take-back schemes

Product-service systems

\begin{abstract}
A B S T R A C T
Society has been operating in a linear way which implies rapid waste generation. Previous research has shown business models able to reclaim products at end-of-use are currently poorly developed and implemented. A shift should be made to Circular Business Models (CBM) that focus on the re-use and recycling of materials. However, little is known about consumers' acceptance and willingness to participate in CBMs. The present study aims to enrich the existing research on CBM consumer acceptance which currently lacks generalisable quantitative insights on preferential CBM design. The consumer intention to participate in three types of CBMs (take-back management, product lease and pay-per-use) is analysed emphasising three key characteristics: ownership, responsibility and payment structure. We use an established consumer behaviour theory, the Theory of Planned Behaviour and extend it with two main factors (environmental attitude and habits) in order to make it apt for analysing consumer preferences regarding environmental decision-making. Results show consumers' clear preference for takeback management models over leasing or pay-per-use models. In particular, habits and consumer opinion regarding payment structures are revealed to have a large influence on consumer intention to participate in CBMs. Altered payment structures in leasing and pay-per use seem a crucial reason for lower acceptance. Ownership on the other hand had a marginal influence, which was not expected based on CBM literature. This suggests that institutionalised consumer habits have to be acknowledged and alternative characteristics have to be introduced gradually to reform habits. The results can serve as guidance for companies in their design and implementation of circular strategies to reclaim products after use. Future research should aim to more deeply understand the relation between consumers acceptance and the responsibility and payment structure characteristics of CBMs.
\end{abstract}

(c) 2020 Elsevier Ltd. All rights reserved.

\section{Introduction}

Over the past centuries, production and consumption in society have mainly operated in a linear way. We make products, we use them, and afterwards we throw them away (Ellen MacArthur Foundation, 2015; Ghisellini et al., 2016). As valuable material is currently being wasted in such linear system, the take-back of old products or components for re-use and recycling might yield tremendous economic and environmental benefits (Lu et al., 2015). Scholars argue that for reversing trends towards waste accumulation and resource scarcity, a shift should be made to an economy that is more circular (Ellen MacArthur Foundation, 2015; Ghisellini et al., 2016).

The 'Circular Economy' is an industrial system that replaces the

\footnotetext{
* Corresponding author.

E-mail addresses: r.elzinga@uu.nl (R. Elzinga), d.reike@uu.nl (D. Reike),s.o. negro@uu.nl (S.O. Negro),w.p.c.boon@uu.nl (W.P.C. Boon).
}

'end-of-life' notion engrained in linear economies with "reducing, alternatively reusing, recycling and recovering materials in production/distribution and consumption processes, with the aim to accomplish sustainable development [...] to the benefit of current and future generations" (Kirchherr et al., 2017, p. 4). Businesses have to re-design their existing linear business models into circular business models (CBMs) in order to build such an alternative logic into production cycles. In CBMs the take-back of old products is of essence to ensure product recycling and preventing their disposal (Ellen MacArthur Foundation, 2013; Ellen MacArthur Foundation, 2015; Lewandowski, 2016; Ghisellini et al., 2016).

Recent studies discuss the development of CBMs and the potential effects on the way businesses create value for companies and customers. The consumer attitude towards these changes, however, remains a critically underexposed aspect (Ghisellini et al., 2016; Planing, 2018). Kirchherr et al. (2017) noticed a general research gap in addressing the consumer perspective towards the Circular Economy. This supports Borrello et al. (2017, p. 1) in their 
statement that "little is known about consumers' willingness to participate in a Circular Economy". Catulli et al. (2017) more specifically state that consumer acceptance of CBMs is heavily under researched, and Ramani et al. (2010) highlight the demand for research on the attitudes and the motivation of consumers to participate in CBMs.

The research gap resonates with the fact that existing studies discuss the redesign of business models (BMs) mainly from a corporate perspective, treating the consumers rather as passive agents. From a practical point of view, this is problematic, as understanding the demand-side and users of innovation is essential in new products, services and business models to become successful (Von Hippel, 2005). Neglecting consumer preferences and behaviour can easily result in the creation of suboptimal or incomplete business models which are unable to grasp the full potential of a Circular Economy (Thøgersen, 1995; Rexfelt \& Hiort af Ornäs, 2009; Lewandowski, 2016; Planing, 2018; Kirchherr et al., 2017).

To study the consumer perspective in CBMs we employ the Theory of Planned Behaviour (TPB) proposed by Ajzen (1985). TPB is a widely used and recognised behavioural framework (Ajzen, 2011; Sniehotta et al., 2014). However, as Bamberg and Möser (2007) outlined, the TPB has limits in the assessment of environmental-related behaviour. This article addresses the research gap related to the consumer perspective on the Circular Economy by applying the TPB and extending it to make the model suitable for analysing environmental-related decision making. The present study aims to enrich the existing literature on consumer acceptance of CBMs which lacks generalisable quantitative insights on preferential CBM design. The study specifically investigates the three proposed key dimensions of CBMs: product ownership, product responsibility and payment structure, and analyses to what extent the design of these three key aspects affects consumer intention to participate in the CBMs.

The research first describes changes in CBMs compared to regular business models, to draw attention to the changes in product ownership, product responsibility and payment structure and how these dimensions affect the consumer. Three different CBMs are studied: the take-back system, the lease model and the pay-per-use model. The consumer preferences for these business models are investigated in the context of the electronics sector and are applied to the case study of Canon Europe, a multi-national producer and retailer of electronic devices ranging from cameras to printers. According to Awasthi et al. (2018), this sector has particular stakes in finding suitable CBMs, as e-waste has become a global problem, especially due to depositing used electronic products in lowincome countries where valuable materials have long been retained through informal and hazardous recycling practices (Reike et al., 2018).

\section{Theoretical framework}

\subsection{Circular business models}

According to Osterwalder and Pigneur (2010) a business model "describes the rationale of how an organisation creates, delivers and captures value" (Osterwalder and Pigneur, 2010, p. 14). Osterwalder and Pigneur (2010) developed a widely applied tool for depicting and analysing BMs: The Business Model Canvas (BMC). The BMC disentangles and displays nine core elements comprised in traditional business models: What value a company aims to create (value proposition); for whom is this value created (customer segment); how is this value delivered to the customer (channels); which resources (key resources) and partners (key partners) are needed in order to create this value; what activities have to be executed to create this value (key activities); the kind of relationships a company aims to establish with its customers (customer relationships); the costs linked to the creation of the product or service value (cost structure) and how this value is capitalised (revenue stream). The BMC enables breaking down these complexities of BMs into single elements and is therefore known for its ease of use and is widely recognised (Lüdeke-Freund, 2010; Barquet et al., 2013).

As far as current research shows, all the basic elements of a regular BM match those of sustainable business models and circular business models. The conceptualization of the different building blocks, however, seems to vary significantly in Sustainable Business Models and CBMs (Lewandowski, 2016) - what constitutes value is extended in line with the principles of sustainability. Next to fulfilling a customer need and creating economic value for society, the value proposition is extended with the creation of environmental and social value for customers, stakeholders and future generations. Consequently, the extended value proposition design gets embedded in the modes of value creation, capture and delivery underlying the business operations (Ellen MacArthur Foundation, 2015; Lewandowski, 2016). Bocken et al. (2014) argue that such extended value propositions allow for innovation which creates durable competitive advantage for companies. A CBM is a particular type of Sustainable Business Model which tends to focus on the environmental and economic dimensions of sustainable value creation even though it can include social aspects (Murray et al., 2017; Geissdoerfer et al., 2017). CBMs generally concentrate on the preservation of resources and the circulation of products and materials in closed loop supply chains to preserve the highest possible value (Kirchherr et al., 2017; Reike et al., 2018). This particular value proposition asks companies to establish reverse flows in order to retain products and materials from consumers and end-of-life processors in the supply chains. In this point, CBMs stand in sharp contrast to linear BMs where a unidirectional flow of products and materials predominates.

Not only the flow of products and goods, but also relationships are fundamentally altered. For example, a CBM might provide access to a product as a service, instead of transferring ownership, to deliver the same value. The consumer can use the product over time while companies control the take-back (Tukker, 2004; Bocken et al., 2014; Lewandowski, 2016).

Such business models wherein extended services are offered to consumers for enabling closed-loop supply chains are called circular Product-Service Systems or service-oriented CBMs (Michelini et al., 2017), and represent a specific sub-class of CBMs. Tukker (2015) distinguishes three types of PSS: Product-oriented, Useoriented, and Result-oriented services.

A closer analysis across these three different types, prior to the current research, revealed that three characteristics of BMs can be identified to experience fundamental reconfiguration in circular PSS which are not directly captured in existing BMC: The product ownership, the product responsibilities, and the product payment structure. These can be viewed as missing distinctions within the design of BMC tailored to analyse CBMs. Accordingly, as proposed in this study, different ownership and responsibility structures are viewed as features of the extended value proposition. Additionally, an altered payment structure, grouped under the revenue stream in the BMC, alters significantly over CBM configurations. Currently, BMC tailored to create or analyse CBMs lack these more finegrained distinctions.

Bocken et al. (2014), in their article on a taxonomy of CBMs, mentions three examples of more specific service-oriented CBMs. The first is termed 'take-back management' which is still largely oriented towards maximising sales like Tukker's category of product-oriented PSS. The lease model is use-oriented as stated by Tukker (2004), and the pay per use is a result-oriented business 
Table 1

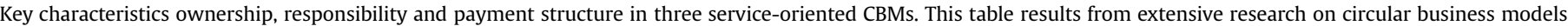
according to the nine BMC elements, prior to the current research.

\begin{tabular}{|c|c|c|c|}
\hline Business model & Ownership & Responsibility & Payment structure \\
\hline Take-back management & $\begin{array}{l}\text { Reobtained by } \\
\text { company through } \\
\text { the use of collection } \\
\text { points and } \\
\text { returning fees }\end{array}$ & $\begin{array}{l}\text { Consumer is responsible for the } \\
\text { functionality of the product }\end{array}$ & One-time transaction in which ownership is sold \\
\hline Product lease & $\begin{array}{l}\text { At company during } \\
\text { entire life cycle }\end{array}$ & $\begin{array}{l}\text { Company is responsible for the } \\
\text { functionality of the product }\end{array}$ & Structured monthly over-time payment \\
\hline Pay-per-use & $\begin{array}{l}\text { At company during } \\
\text { entire life cycle }\end{array}$ & $\begin{array}{l}\text { Consumer is completely } \\
\text { unburdened and can always } \\
\text { make use of the service }\end{array}$ & Consumer pays each time the product or service is used \\
\hline
\end{tabular}

model focused on temporal access. Table 1 relates the three specific service oriented CBMs mentioned by Bocken et al. (2014) to Tukker's (2004) more comprehensive work on altered structures and responsibilities between the producers and consumers in circular and resource efficient BMs.

As a first characteristic, ownership of the product is assumed to vary as a value proposition characteristic over these three different service-oriented CBMs consumers (Tukker, 2004; Bocken et al., 2014; Lewandowski, 2016). A distinction can be made between ownership during and after use. The first identified model, takeback management (TBM), resembles linear BMs wherein ownership is transferred from producer to consumer at the moment of purchase and retained by the consumer during use. Some consumers value ownership more than access to the functionality of a product, in particular with luxury goods functioning as status symbols such as cars (Gatersleben, 2011). It can be argued that purchasing permanent ownership and thereby full control of use and after-use is an integral part of the value proposition in certain BMs (Table 1). However, unlike in linear BMs, this service-oriented CBM asks the consumer to give up after-use ownership and to participate in take-back schemes. This requires the company or its partners to provide incentives to the consumer, effectively enabling them to reobtain ownership at end-of-use. It is noteworthy that, gathering and processing of the product after-use can be performed by potentially any party with or without link to the regular supply chain. The two other CBMs types, product lease and pay-per-use sell services which give consumers access to the product but wherein ownership is retained by the provider during use and after-use. Reuse and recycling are more easily accomplished in these two CBMs, as producers easily keep track and ownership of all products in a CBM where access to the product for the consumer is entangled with the services offered by the producer such as repair and maintenance (Guide et al., 2003).

The second characteristic, responsibility, shows varying configurations over the three identified CBMs (Table 1). In the TBM, customers are fully responsible for the product and bear repair and maintenance cost similar to a traditional BM. Within the lease model, responsibility shifts to the service provider. Herewith, companies unburden customers by offering support with repair and maintenance and provide necessities. Pay-per-use fully unburdens customers, as it provides a complete service in which a result is guaranteed (Barquet et al., 2013). Alongside, companies sometimes provide preventive maintenance ensuring continuous

\footnotetext{
1 Table 1 links theoretical elements of PSS proposed by Tukker to three specific service-oriented CBMs proposed by Bocken et al. (2014). Rather than drawing these links merely based on assumptions in the literature, the authors' conducted prior analysis focussing on the changes in the nine BMC elements, when addressing CBMs, as background for creating the matrix. This data remains available upon request.
}

product performance. Tukker (2015) claimed that the shift in responsibility, causing repair costs to be incurred by the provider of the product and services, leads to an adapted focus of product designers within the value chain on durability, longevity and quality of products as to minimize costs and maximize benefits from offering the services.

As part of the revenue streams, the payment structure is fundamentally altered within most service-oriented CBMs deviating from a typical one-off product for payment transaction. TBM compares to classic BMs in design in which a single transaction is common practice. The Lease model typically makes use of a structured payment method based on instalments paid over-time. When shifting to more circular BMs, a monthly payment becomes more likely. Customers pay a monthly fee to gain access to a product or a delivered service, or, as in the pay-per-use models, every time the service or product is used (Barquet et al., 2013). The pay-per-use model asks for the most fundamental shift in relationships as charges apply to the consumer exclusively for access to the product during use. At the same time, this allows for the creation of charging schemes tailored exactly to customer needs thereby eliminating any unnecessary idle cost for the consumer.

\subsection{Theory of Planned Behaviour}

It has been acknowledged that consumers tend to base their choice hardly on rational motives but tend to rely on more emotional and subjective beliefs and attitudes towards a product in the decision-making process (Fishbein and Ajzen, 2010). Beliefs, habits, knowledge and social norms were pointed to be core influencers of attitude (Thøgersen, 1995; Fishbein and Ajzen, 2010).

The Theory of Planned Behaviour is a behavioural framework dealing with beliefs, attitudes and intention (TPB; Fig. 1) (Ajzen, 1985). The TPB was developed by Ajzen (1985) and has earned a distinct reputation compared to other behavioural frameworks through extensive application over the last three decades (Ajzen, 2011; Sniehotta et al., 2014). The TPB was derived from the Theory of Reasoned Action (TRA) developed by Fishbein and Ajzen (1975) and is most commonly used in health-related behavioural research (Sniehotta et al., 2014). We propose to apply the TPB to explore CBM characteristics in a consumer context, as the theory acknowledges the importance of both intentions and attitudes influencing exposed consumer behaviour.

In the framework proposed by Ajzen (1985), illustrated in Fig. 1, the outcome variable 'behaviour' is directly influenced by the 'will to perform a behaviour', intention, which is supported by previous research (Sheeran, 2002; Webb and Sheeran, 2006). However, the TPB is criticised for not including habits and past behaviour (Ajzen, 2011). For example, Klöckner (2013) states the TPB to have no predictive value over repeated behaviour, especially in the context of environmental related decision making. In addition, in a meta- 


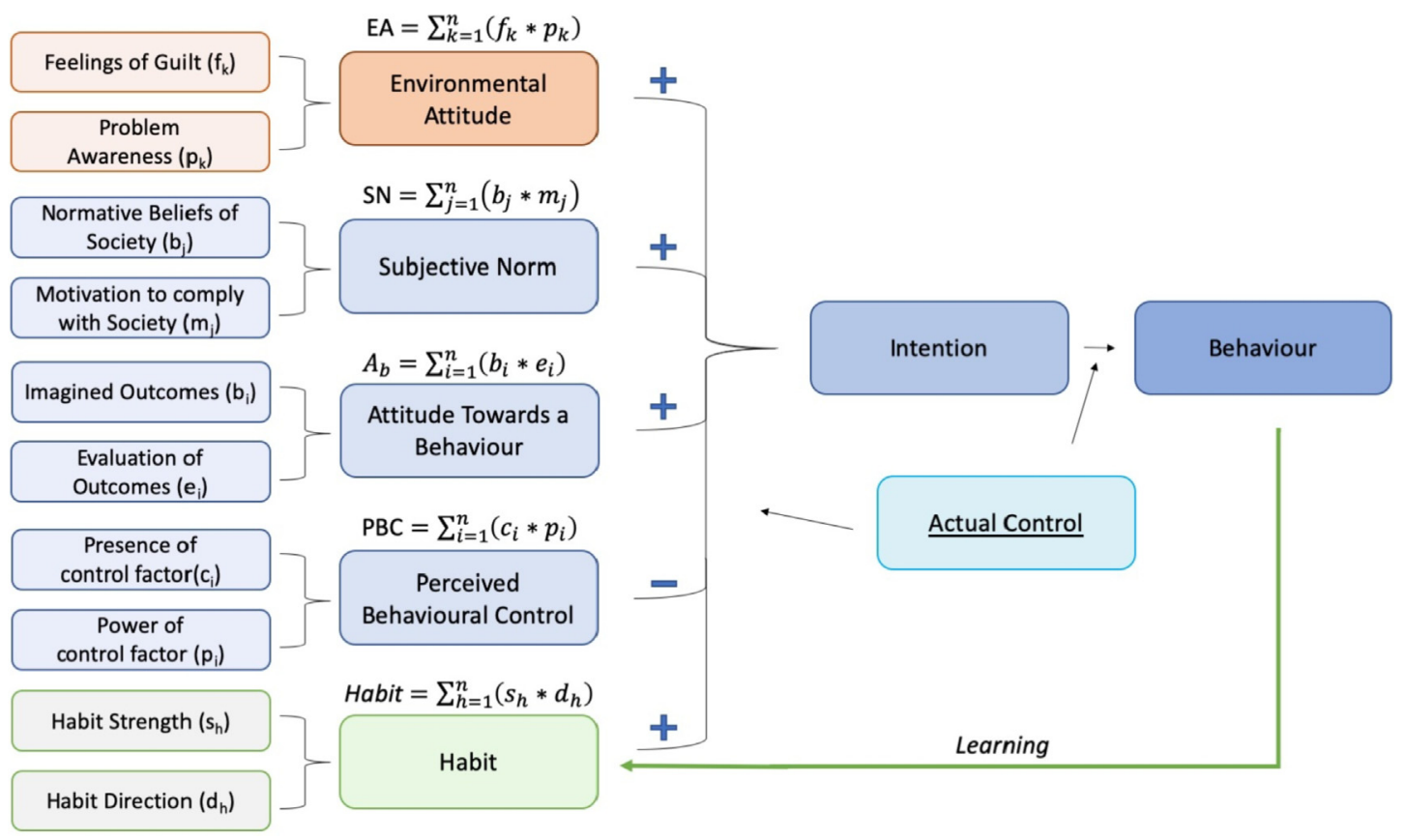

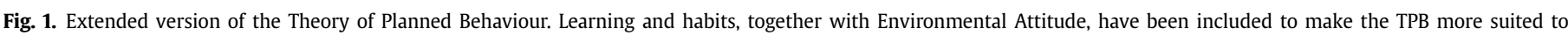

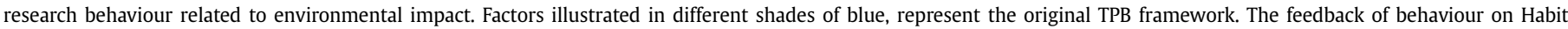

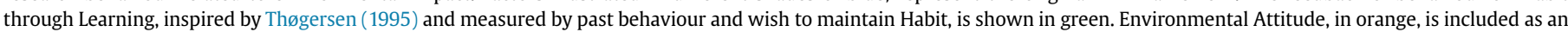

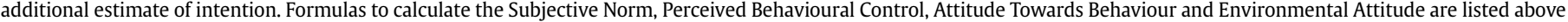
the corresponding factor.

analysis of Gardner et al. (2011), habit strength was assumed to have significant effect on the prediction of behaviour. Quite a number of researchers support the inclusion of habit as an influencer of behaviour to enriching behavioural models focussing on environmental impact (Bagozzi, 1982; Thøgersen, 1995; Stern, 2000; Hagger et al., 2002; Bamberg and Möser, 2007). Next to habits, Bamberg and Möser (2007) reviewed studies which assessed environmental related decision making and concluded problem awareness to have a significant influence on intention. Therefore, this research introduces two additional factors in the original Theory of Planned Behaviour framework: habits (as an indicator of past behaviour) and environmental attitude (Fig. 1).

As proposed by Thøgersen (1995), learning from past experience is being included in the model through habit. A habit is defined as a 'behaviour repeated over time' and has shown to improve the predictability of behaviour (Triandis, 1977; Kok and Siero, 1985; Pieters, 1991; Verplanken and Holland, 2002), and is measured by 'past behaviour', but also by the 'wish to maintain the habit' (Harich, 2010). Harich (2010) argues the wish to maintain old habits might be the crux in the shift to a sustainable society. Therefore, it is argued that the willingness to change old behaviour can affect intention and the uptake of CBMs. In this study, habits are assessed by the habit direction, measured by the extent to which the current habit is in line with the envisioned behaviour, and to what extent someone is willing to change its old habit, named habit strength (Fig. 1).

As a second extension, environmental aspects and motives are integrated into the TPB and addressed through the environmental attitude (EA). EA represents a person's motivation to act environmentally friendly. In this study, it is measured as making use of the two most dominant mentioned factors by Bamberg and Möser (2007), namely problem awareness and feelings of guilt. More concretely, environmental attitude is described as consumers awareness over current environmental issues and their feelings of guilt over the human caused nature of these issues. This relates less to consumers' actual access and level of information on environmental problems, but to the extent to which consumers believe to be aware of the environmental problems (Bagozzi and Dabholkar, 1994) (Fig. 1). The TPB originally includes environmental considerations through subjective norm, but this is criticised by Thøgersen (1995). Studies investigation environmental awareness, resulted in wide varying results among the research population, which makes SN an unstable and unreliable predictor for environmental norms (Thøgersen, 1995). Moreover, concerns have been formulated by Ajzen (2011) about linking new factors to already existing predictors of intention, as it might hamper the predictive value of the linked factor. Ajzen $(2006,2011)$ also stated that additional factors can be included in the TPB, as long as they do not build on already set beliefs but can be measured as independent estimates of intention. Following his recommendation for retrieving sound results with our TPB extension, environmental attitude and habit are considered as additional factors influencing intention, when investigating consumer behaviour related to a Circular Economy (Fig. 1).

\section{Methods}

The following section explains how the identified specific CBM features (ownership, responsibility and payment structure) and their variation over the three CBM types can be linked to the TPB to explore consumer preferences in CBM characteristics. The TBP assumes that measuring intention provides insight into the underlying cognitive foundation that determines the actual behaviour in practice. In this study, 'intention' represents the intention to adopt one of the three types of CBM. Through measuring the characteristics ownership, responsibility and payment structure linked to intention, it is possible to measure the willingness to adopt to service-oriented CBMs. 


\subsection{Operationalisation}

The key variable intention represents the 'willingness to act' in Ajzen (1985) framework. Willingness to act (intention) is composed of three different factors: Attitude towards the behaviour (ATB), subjective norm (SN) and perceived behavioural control (PBC).

ATB is assumed to rely on the sum of the likelihood of imagined outcomes from acting, multiplied by the score of its importance (Fishbein and Ajzen, 2010). The numeric formula, also shown in Fig. 1, can be displayed as $A_{b}=\sum b_{i} e_{i}$, in which $A_{b}$ is the ATB, $b_{i}$ is the person's opinion regarding the action resulting in outcome $i$, and $e_{i}$ is the personal judgement or evaluation of outcome i. SN can be constructed by multiplying normative beliefs (b) of other people (j), with a person's desire to comply with those beliefs of person $j$ $\left(\mathrm{SN}=\Sigma \mathrm{b}_{\mathrm{j}} \mathrm{m}_{\mathrm{j}}\right)$. Likewise, $\mathrm{PBC}$ is calculated by the sum of all belief $(\mathrm{l})$ of a control factor (c) being present, multiplied by the power of the factor (f) " $\mathrm{i}$ " to inhibit or facilitate the behaviour ( $\mathrm{PBC}=\Sigma \mathrm{c}_{\mathrm{f}} \mathrm{f}_{\mathrm{l}}$ ).

Herewith, intention is a product of: all positive and negative associations with the behaviour in question, weighted by the evaluation of outcomes; SN which is generated by the beliefs of other people or society, weighted with a person's desire to comply with those beliefs; and PBC constructed by feelings of control (Fig. 1). PBC is often studied in the context of abdication, i.e. control behaviours are studied which prohibit someone from converting an intention into behaviour (Fishbein and Ajzen, 2010; Ajzen, 2011). Ajzen and others found the beliefs represented by these three concepts provided essential information about the willingness to perform, or abstain from performing, a specific behaviour (Fishbein and Ajzen, 2010; Ajzen, 2011).

Congruent with the original TPB, in this study intention to perform a specific behaviour is expected to be high when the SN and ATB are high, and the PBC is considered low (Fig. 1). However, as argued for in Section 2.2, two additional factors are included in the TPB: The consumer environmental attitude (EA) and habits (habit). Intention to participate in CBM is expected to increase with a high EA as a positive attitudes towards the environment can be associated with conservation and therefore indicate higher willingness to adopt CBMs. EA is estimated by multiplying problem awareness $(\mathrm{p})$ of ecological problems $(\mathrm{k})$ with the feelings of guilt (f) over the ecological problem (k) $\left(\mathrm{EA}=\Sigma \mathrm{f}_{\mathrm{k}} \mathrm{p}_{\mathrm{k}}\right)$ (Fig. 1).

The second addition to the TPB is 'habit' which is measured in habit strength and habit direction. A strong habit indicates a person is unwilling to change it. Intention to participate or not participate in a CBM is expected to be influenced greatly by strong habits, as these are assumed to be deeply rooted beliefs and difficult to change. Conversely, when habits are not long-standing and strong, they can usually be altered more easily, and are expected to have only a minimal effect on the intention to execute a certain behaviour. Habit direction indicates if the existing habits are leaning towards or against the intended behaviour and questions were conceptualised or formulated to stimulate the adjustment to the envisioned behaviour accompanying the CBM characteristic. The influence of habit $\left(\Sigma s_{h} d_{h}\right)$ has been measured as a product of multiplying the habit's strength $\left(s_{h}\right)$ with the habit direction $\left(d_{h}\right)$.

In this study, the above described measurements were used to map consumer attitude, social norms, control factors, habits and environmental awareness regarding the varying CBM characteristics ownership, responsibility and payment structure. Like in most TPB research, a questionnaire was used. Questions were constructed to measure the influence of each variable on each of the CBM characteristics for all three CBMs. Herewith, nine regression models were established. Below the exact methods applied for data collection and analysis are further outlined including a specific example illustrating the link among the questionnaire and measurement (section 3.3).

\subsection{Data collection}

In the first stage of this research, in line with TPB research standards, a pilot study, with open-ended questions, was conducted to identify accessible behavioural, normative, and control beliefs, to be assessed in the main survey (Ajzen, 1991; De Leeuw et al., 2015). Pilot respondents $(\mathrm{N}=24)$ were asked to list likely outcomes, normative beliefs, and control factors that came readily to mind, when being asked what they associate with each of the three CBMs analysed in this study. These results were ranked according to frequency of occurrence, to determine the respondents most readily accessible beliefs likely to be present in the target group. Beliefs identified in the pilot study, were used to formulate the closed questions in the main survey and served as direct measurements of EA, SN, ATB, PBC and intention (Ajzen, 1991). The main survey was used to assess respondents $(\mathrm{N}=537)$ beliefs concerning and intention to CBM in a quantitative fashion.

\subsection{Questionnaire}

In order to formulate questions, a 7-point bipolar scale was applied as previous research has shown a scale of this size is most suitable in TPB-related research (Ajzen, 2015). Table 2 provides example questions within the CBM Take-Back Management. The characteristic ownership was taken as an example to clarify the measurement.

As shown in section 3.1, the measurement for ATB is obtained by multiplying the imagined outcomes by the score of its importance $(\mathrm{Ab}=\Sigma$ biei) (Fig. 1). To illustrate, if a respondent agrees with the first statement in Table 2 ("I think it's good that cartridges were to be collected after use") and does not perceive handing in a cartridge to take a lot of effort, he or she would provide high scores on both questions, for example " 6 ". By use of the formula listed above, ATB would score $36\left(6^{*} 6\right)$ out of the maximum $49\left(7^{*} 7\right)$. As the willingness to participate in CBMs is measured through intention as a single parameter, scores can only vary between 1 and 7 .

\subsection{Sample size and research population}

A particular interesting sector to study consumer acceptance of CBMs is the electronics industry. The production and consumption of electronic products and services has a high environmental impact which occurs in the use phase. Insights into CBMs are relevant for companies in this sector, as these are increasingly held accountable for impacts over the entire lifecycle of products rather than production and end-of use impacts. This research focuses on Canon Europe as a case study and specifically on the Dutchbusiness-to-consumer (B2C) printer imaging market. Printers are a good example of products with high impacts in the use phase. With the support of Canon, we were able to access their extensive database of registered consumers which results in a research population of almost 1 million registered contacts linked to printer solutions in the Netherlands alone. With such a research population and an adopted error margin of 5 percent, at least 400 responses are required (Bryman, 2015). This research surpasses this threshold with a total of 537 responses $(n=537)$. Next to that, we also identified the candidates for the pilot survey through the Canon database. To summarise, both questionnaires were sent to registered contacts from the Canon database and the questions addressed the Dutch B2C printer imaging market.

\subsection{Analysis}

The data from the questionnaire was subdivided into three different groups corresponding to the three different types of CBMs. 
Table 2

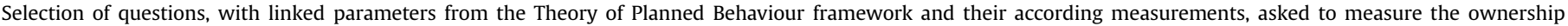
characteristic and intention over the Take-Back Management model.

\begin{tabular}{|c|c|c|}
\hline Variables & Indicators & Question \\
\hline ATB & $\begin{array}{l}\text { Imagined Outcomes }\left(\mathrm{b}_{\mathrm{i}}\right) \\
\text { Evaluation of outcomes }\left(\mathrm{e}_{\mathrm{i}}\right)\end{array}$ & $\begin{array}{l}\text { I think it's good that cartridges were to be collected after use } \\
\text { Disagree: } \_1 \_:-2 \_:-3 \_:-4 \_: \_5 \_:-6 \_:-7 \_ \text {: Agree } \\
\text { I would take the effort to hand in my cartridge, after use, at a local collection point } \\
\text { Most probably not: _1_:_2_:_3_:_4_:_5_:_6_:_7_: Probably not }\end{array}$ \\
\hline SN & $\begin{array}{l}\text { Normative belief of society }\left(b_{j}\right) \\
\text { Motivation to comply with society }\left(\mathrm{m}_{\mathrm{j}}\right)\end{array}$ & $\begin{array}{l}\text { I think others would hand in their cartridges } \\
\text { Disagree: } \_1 \_: \_2 \_ \text {__ } 3 \text { :_4_:_5_:_6_:_7_: Agree } \\
\text { If others would hand in their cartridge after use, I would do so too. } \\
\text { Probably not:_1_:_2_:_3_:_4_:_5_:_6_:_7_: Most probably }\end{array}$ \\
\hline PBC & $\begin{array}{l}\text { Sense of control factor being present }\left(c_{i}\right) \\
\text { Power of control factor }\left(p_{i}\right)\end{array}$ & $\begin{array}{l}\text { I think it will take ... effort to hand in my cartridge } \\
\text { Little: } \_1 \_: 2 \_ \text {__3_:_4_:_5_:_6_:_7_: A lot of } \\
\text { The amount of effort it will take to hand in my cartridge will ... influence } \\
\text { my willingness to hand in my cartridge } \\
\text { Not at all:____:_2_:_3_:_4_:_5_:_6_:_7_: Strongly }\end{array}$ \\
\hline Intention & Intention to participate in TBM & $\begin{array}{l}\text { I would take part in a model in which I, after use, hand over ownership } \\
\text { of the product for a compensation } \\
\text { Probably not:_1_:_2_:_3_:_4_:_5_:_6_:_7_: Most probably }\end{array}$ \\
\hline
\end{tabular}

For each group, the median was listed, as it copes better with outliers and skewed data. Then, correlations to intention were tested. These correlations were created by the use of multiple regressions. With the Beta-coefficients obtained from the multiple regression, the relative contribution to intention of the factors ATB, SN PBC, EA and habit were measured. By making use of multiple regression, models with the aim of predicting intention were constructed. Hereby, it can be evaluated which CBM is favoured by the consumer and which factor, within which business model characteristics, explains most of the observed variance in intentions.

\section{Results}

Section 4 displays and discusses the obtained results from the multiple regression models.

First, Table 3 grants an overview of the results of all regression models which is followed by descriptive results and tables for each of the three measured CBM types.

\subsection{Take-back management}

Looking at TBM, the first out of three studied CBM types, consumers' willingness or intention to adopt this CBM is remarkably high ( $\mathrm{Mdn}=7$ on a 7-point scale) (Table 4 ). The habit parameters linked to the current responsibility distribution and payment form influence intention five times as much as the other parameters in the model (SCBeta $=0.56$; SCBeta $=0.52$ ) (Table 3 ). This could be explained by the way responsibility and payment structure are designed within the take-back management model, as they resemble the design of established linear business models and therefore correspond with the habits in place. The large influence of habits, which are shaped and focussed on past and current behaviour, can be linked to the comparable design of the take-back management model (Verplanken and Holland, 2002).

The attitude towards the envisioned behaviour of the consumer, concerning ownership and responsibility, seem to influence intention the least is this model (Table 3). However, the opinion of the consumer towards handing over product ownership after use (OWN-ATB) scores high ( $\mathrm{Mdn}=49$ on a 49-point scale) (Table 4 ), meaning consumers would like to hand in their used products. Therefore, this factor still has profound impact on the observed intention. In TBMs, ownership is the only characteristic in this CBM that is fundamentally different from linear BMs. The high measured score on attitude towards ownership can be explained by or linked to the high score on environmental attitude, as the shift of ownership could easily be perceived as recycling. Based on the result, it can be proposed that the environmental concern of the consumer fosters the consumers' attitude of relinquishing product ownership (OWNATB). The link between these parameters is also visible in the data, as the two variables significantly correlate (Table 4).

As expected, possible struggles related to handing over product ownership (OWN-PBC) negatively influences intention, but due to its low median score and influence, we conclude that this parameter did not have a profound impact on intention in this study (Table 3; Table 4).Altogether, the results suggest that consumers base their decision to participate or to abstain from participation in the takeback management model on their attitude concerning the foreseen struggles linked to handing in products after use, attitude over being responsible for products themselves, environmental attitude, and most strongly by their habits concerning payment form and responsibility distribution (Intention $=0.084^{*}(\mathrm{RES}-\mathrm{ATB})+0.086^{*}(\mathrm{OWN}-$ ATB $)+0.11^{*}(\mathrm{EA})-0.11^{*}(\mathrm{OWN}-\mathrm{PBC})+0.56^{*}(\mathrm{RES}-$ Habit $)+0.52^{*}(\mathrm{PS}-$ Habit)) (Table 3$)$. At the same time, the TBM-model only accounts for 16.7 percent of the observed variance, which, according to Cohen's (1988) work, makes it a weak model.

\subsection{Product lease}

Only three variables have a significant influence on the model describing consumers' willingness (intention) to engage in the Lease type CBM. Yet following Cohen's (1988) threshold on predictive power, these three variables together form a strong predictive model by representing 27.3 percent of the observed variance (Table 3).

Remarkable is the significant drop in intention $(\operatorname{Mdn}=1)$ compared to the first CBM type (TBM) and the strong influence of the payment structure parameters in this model. As listed in Table 5, scores concerning consumer opinion regarding paying per month (PS-ATB) $(\mathrm{Mdn}=4)$ and consumers familiarity with paying $a$ month (PS-Habit) (Mdn =7) are very low. At the same time, the struggle associated with paying per month (PS-PBC) is quite high $(\mathrm{Mdn}=28)$, meaning the majority of the respondents expects to encounter negativities while paying per month. Furthermore, the factors consumer opinion regarding paying per month (PS-ATB) $(\mathrm{Mdn}=4)$ and consumers familiarity with paying a month (PS-Habit) $(\mathrm{Mdn}=7)$ hamper intention to participate in Lease. The negative influence of habits related to concerning paying per month (PS-Habit) could be expected as habits are formed to the current market 


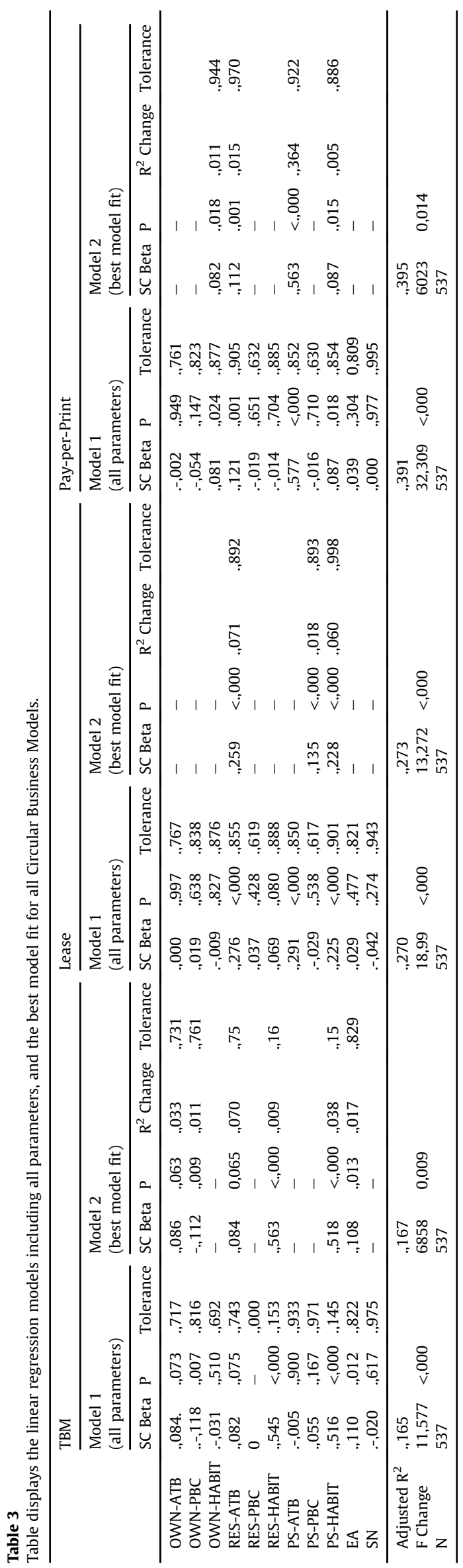

design and do not suit a monthly payment structure. The low score measured, however, is mostly arising from the direction of the habit, not its strength.

Herewith, it could be argued these habits can be changed, once the consumers opinion is in favour of a monthly payment structure. On the other hand, inspecting the low score observed from consumers opinion about paying a month (PS-ATB), it could be questioned if consumers are willing to shift to an alternative payment structure at all (Table 5). According to Ouellette and Wood (1998), innovative intentions can be successfully transformed to new habits, once they result in a pleasant behaviour repeated over time. However, consumers perceive no advantages but rather disadvantages from the new monthly payment and is therefore unlikely to facilitate a behavioural shift. Therefore, it could be stated the low scores for consumer attitude regarding paying per month (PS-ATB) and habit direction regarding paying per month (PS-Habit) have a strong negative influence on present and future intention towards the Lease model.

The third and final parameter influencing Intention in this model is the consumers opinion over product responsibility (RESATB) (Table 3). In the Lease model, responsibility shifts from the consumer towards the producer (Fig. 1). Reflecting on Table 5, this parameter appears to be the highest significant factor, which has a positive influence on intention. This result indicates the wish of the consumers for unburdening of inconveniences, which could be realised through shifting product responsibility to the product and service providers (Lewandowski, 2016). However, the prospect of unburdening consumers, in the present analysis, cannot balance the negative influence of the payment structure parameters. Altogether intention still scores remarkably low $(\operatorname{Mdn}=1)$.

Overall, intention towards the Lease CBM is determined by the consumers opinion over the monthly payment structure and the outsourcing of product responsibility, together with consumers familiarity to monthly payment structures (Table 3 ) (Intention $=0.287^{*}$ (PSATB $)+0.273^{*}($ RES-ATB $)+0.246^{*}($ PS-Habit $)$.

\subsection{Pay-per-print}

In the third CBM type, Pay-per-use or 'Pay-per-print', the intention is measured to be low ( $\mathrm{Mdn}=1$ on a 7-point scale). The most dominant parameter in this CBM is consumer attitude towards paying per use (PS-ATB), with an influence five times as strong as all other measured variables (Table 3). The consumers opinion concerning the new payment forms is once more the most negative factor in the model (Table 3; Table 6). This reaffirms the results from the Lease type PSS in Table 5 of consumers being sceptic towards new forms of payment. The low score $(\mathrm{Mdn}=4)$ and strong influence in the model (SCBeta $=0.564$ ) of consumers opinion concerning the new payment structures indicate that the low intention towards the pay-per-print model ( $\mathrm{Mdn}=1$ ) is mostly explained by this parameter. Similarly, as in the Lease model, consumers attitude towards responsibility (RES-ATB) can be viewed as a counteracting factor making a positive, but moderately strong, contribution to the outcome of the model.

Furthermore, scores for habits concerning the payment structure are low, as consumers are not used to such payment structures. Habits regarding ownership, or if consumers are used to hand-in products after use, is the last factor in this model. Although its contribution is limited, its influence on intention is positive. The presence of this parameter indicates the link between the takeback of old product is, from a consumer perspective, more strongly present in Pay-per-Use BM than in Lease models (Table 3).

Comprehensively, intention towards the pay-per-print Circular Business Model is most strongly influenced or determined by the consumers opinion concerning paying per print but also affected the 
Table 4

Table shows descriptive statistics of the Take-back model. Listed are Median and correlations between all variables. Variables are shown in abbreviations. OWN=Ownership, RES = Responsibility and PS=Payment Structure. Example wise, OWN-ATB represents the Attitude towards the Ownership characteristics of TBM (shown in Fig. 1). Abbreviations represent combinations of characteristics and parameters from the extended Theory of Planned Behaviour framework, as listed in section 3.1. Theoretical range $1-7={ }^{\mathrm{a}}$, Theoretical range $1-49={ }^{\mathrm{b}}, \mathrm{p}<.05={ }^{*}, \mathrm{p}<.01={ }^{* *}, \mathrm{n}=537$.

\begin{tabular}{|c|c|c|c|c|c|c|c|c|c|c|c|c|c|}
\hline Variable & Median & 1 & 2 & 3 & 4 & 5 & 6 & 7 & 8 & 9 & 10 & 11 & 12 \\
\hline 1. Intention & $7^{\mathrm{a}}$ & - &, $260 * *$ &,$- 187^{* *}$ &,- 025 &, $264^{* *}$ &, $073^{*}$ &, $075^{*}$ &,$- 075^{*}$ &, $073^{*}$ & ,086* &, $224^{* *}$ & ,009 \\
\hline 2. OWN-ATB & $49^{\mathrm{b}}$ & & - &,$- 361^{* *}$ & ,047 & $344^{* *}$ & ,053 &,- 012 &,$- 146^{* *}$ & ,053 & $151^{* *}$ &, $305^{* *}$ & $104^{* *}$ \\
\hline 3. OWN-PBC & $4^{\mathrm{b}}$ & & & - &,$- 087^{*}$ &,$- 205^{* *}$ & ,094* & $0,92^{*}$ &, $207^{* *}$ & ,094* &,$- 128^{* *}$ &,$- 120^{* *}$ & ,009 \\
\hline 4. OWN-Habit & $21^{\mathrm{b}}$ & & & & - &,- 041 & ,005 &,$- 537^{* *}$ & 007 & ,005 &, $528^{* *}$ &, $139 * *$ &,- 052 \\
\hline 5. RES-ATB & $49^{\mathrm{b}}$ & & & & & - & 015 &, 040 &,$- 120^{* *}$ & ,015 & $160^{* *}$ & $208^{* *}$ & 016 \\
\hline 6. RES-PBC & $42^{\mathrm{b}}$ & & & & & & - & 024 &, $074^{*}$ & $1,00^{* *}$ & ,013 & ,039 & ,057 \\
\hline 7. RES-Habit & $36^{\mathrm{b}}$ & & & & & & & - &,- 043 & ,024 &,$- 894^{* *}$ &,$- 154^{* *}$ &, $074^{*}$ \\
\hline 8. PS-ATB & $10^{\mathrm{b}}$ & & & & & & & & - &, $074^{*}$ &,- 008 & ,004 & ,028 \\
\hline 9. PS-PBC & $42^{\mathrm{b}}$ & & & & & & & & & - & ,013 & ,039 & ,057 \\
\hline 10. PS-Habit & $35^{\mathrm{b}}$ & & & & & & & & & & - &, $280^{* *}$ &,- 061 \\
\hline 11. EA & $39^{\mathrm{b}}$ & & & & & & & & & & & - & ,062 \\
\hline 12. SN & $25^{\mathrm{b}}$ & & & & & & & & & & & & - \\
\hline
\end{tabular}

Table 5

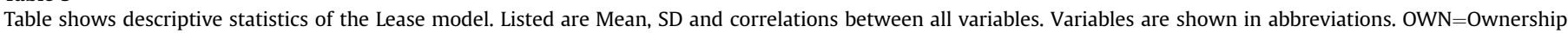

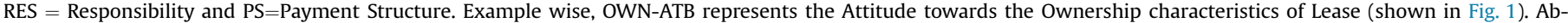

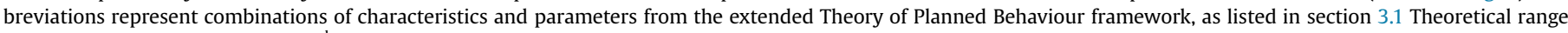
$1-7={ }^{\mathrm{a}}$, Theoretical range $1-49={ }^{\mathrm{b}}, \mathrm{p}<.05={ }^{*}, \mathrm{p}<.01={ }^{* *}, \mathrm{n}=537$.

\begin{tabular}{|c|c|c|c|c|c|c|c|c|c|c|c|c|c|}
\hline Variable & Median & 1 & 2 & 3 & 4 & 5 & 6 & 7 & 8 & 9 & 10 & 11 & 12 \\
\hline 1. Intention & $1^{\mathrm{a}}$ & - &,- 016 & ,080* & ,094* &, $377^{* *}$ & ,020 &, $137^{* *}$ &, $381^{* *}$ &,- 055 &, $261^{* *}$ & ,058 &,- 006 \\
\hline 2. OWN-ATB & $49^{b}$ & & - &,$- 361^{* *}$ &, 047 &, 028 &, $202^{* *}$ &, $073^{*}$ &,$- 118^{* *}$ &, $114^{* *}$ &, 019 &, $305^{* *}$ &, $104^{* *}$ \\
\hline 3. OWN-PBC & $4^{\mathrm{b}}$ & & & - &,$- 087^{*}$ & ,096* &,$- 080^{*}$ & $-0,79^{*}$ & $173^{* *}$ &,- 18 &,- 020 &,$- 120^{* *}$ & ,009 \\
\hline 4. OWN-Habit & $21^{\mathrm{b}}$ & & & & - & ,064 & ,023 & $261^{* *}$ &, 022 &,- 025 &, $246^{* *}$ &, $139^{* *}$ &,- 052 \\
\hline 5. RES-ATB & $16^{\mathrm{b}}$ & & & & & - &, 047 & ,068 & $328^{* *}$ &,- 063 &, 040 &, 035 & $108^{* *}$ \\
\hline 6. RES-PBC & $28^{\mathrm{b}}$ & & & & & & - & ,001 &,$- 116^{* *}$ &, $579^{* *}$ & 059 & $215^{* *}$ &,$- 080^{*}$ \\
\hline 7. RES-Habit & $7^{\mathrm{b}}$ & & & & & & & - & ,002 &,- 063 & $220^{* * *}$ & $102^{* *}$ & ,041 \\
\hline 8. PS-ATB & $4^{\mathrm{b}}$ & & & & & & & & - &,$- 106^{* *}$ & ,016 &,- 007 & $079^{*}$ \\
\hline 9. PS-PBC & $28^{\mathrm{b}}$ & & & & & & & & & - &,- 012 &, $273 * *$ & 016 \\
\hline 10. PS-Habit & $7^{b}$ & & & & & & & & & & - &, $090^{*}$ &,- 080 \\
\hline 11. EA & $39^{b}$ & & & & & & & & & & & - & ,062 \\
\hline 12. SN & $25^{\mathrm{b}}$ & & & & & & & & & & & & - \\
\hline
\end{tabular}

Table 6

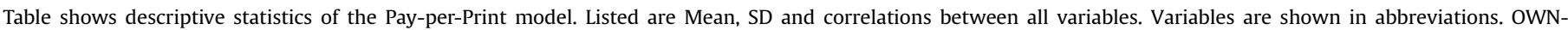

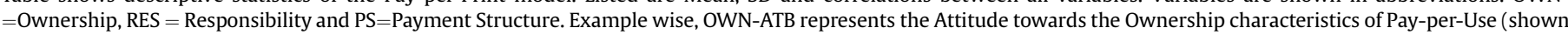

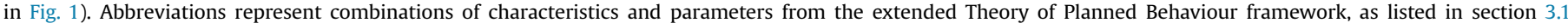
Theoretical range $1-7={ }^{\mathrm{a}}$, Theoretical range $1-49={ }^{\mathrm{b}}, \mathrm{p}<.05={ }^{*}, \mathrm{p}<.01={ }^{* *}, \mathrm{n}=537$.

\begin{tabular}{|c|c|c|c|c|c|c|c|c|c|c|c|c|c|}
\hline Variable & Median & 1 & 2 & 3 & 4 & 5 & 6 & 7 & 8 & 9 & 10 & 11 & 12 \\
\hline 1. Intention & $1^{\mathrm{a}}$ & - &,- 050 & ,079* &, $109^{* *}$ &, $220 * *$ &,- 064 &, $104^{* *}$ &, $603^{* *}$ &,$- 091^{*}$ &, $257^{* *}$ & ,021 & ,011 \\
\hline 2. OWN-ATB & $49^{\mathrm{b}}$ & & - &,$- 361^{* *}$ &, 047 & $122^{* *}$ &, $202^{* *}$ & ,007 &,$- 151^{* *}$ &, $121^{* *}$ &,- 055 &, $305^{* *}$ & $104^{* *}$ \\
\hline 3. OWN-PBC & $4^{\mathrm{b}}$ & & & - &,$- 087^{*}$ & 049 &,$- 080^{*}$ & $-0,048$ &, $230^{* *}$ &,- 026 & ,033 &,$- 120^{* *}$ &, 009 \\
\hline 4. OWN-Habit & $21^{\mathrm{b}}$ & & & & - & 049 & ,023 &, $262^{* *}$ &,- 008 &,- 032 &, $226^{* *}$ &, $139^{* *}$ &,- 052 \\
\hline 5. RES-ATB & $24,5^{\mathrm{b}}$ & & & & & - & $121^{* * *}$ & $129^{* *}$ &, $152^{* *}$ &, 023 &, $112^{* *}$ & $152^{* *}$ &, 043 \\
\hline 6. RES-PBC & $28^{\mathrm{b}}$ & & & & & & - &,- 050 &,$- 113^{* *}$ &, $571^{* *}$ &,- 004 &, $215^{* *}$ &,$- 080^{*}$ \\
\hline 7. RES-Habit & $6^{\mathrm{b}}$ & & & & & & & - & ,095* &,- 067 &, $213^{* *}$ &, 070 & 010 \\
\hline 8. PS-ATB & $4^{\mathrm{b}}$ & & & & & & & & - &,$- 125^{* *}$ &, $241^{* *}$ &,$- 085^{*}$ & ,027 \\
\hline 9. PS-PBC & $28^{\mathrm{b}}$ & & & & & & & & & - &,- 058 &, $280^{* *}$ & 0,13 \\
\hline 10. PS-Habit & $7^{\mathrm{b}}$ & & & & & & & & & & - &, 065 &,$- 097^{*}$ \\
\hline 11. EA & $39^{b}$ & & & & & & & & & & & - &, 062 \\
\hline 12. SN & $25^{\mathrm{b}}$ & & & & & & & & & & & & - \\
\hline
\end{tabular}

Table 7

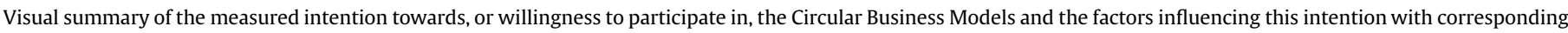
slopes. Factors were listed according to influence on intention, by descending value.

\begin{tabular}{|c|c|c|c|c|c|c|c|c|c|c|c|}
\hline Business model & Intention (median) & factor & slope & factor & slope & factor & slope & factor & slope & factor & slope \\
\hline Take-back management & 7 & RES-Habit & 0.56 & PS-Habit & 0.52 & EA & 0.11 & OWN-ATB & 0.086 & RES-ATB & 0.084 \\
\hline Product lease & 1 & PS-ATB & 0.287 & RES-ATB & 0.273 & PS-Habit & 0.246 & - & - & - & - \\
\hline Pay-per-use & 1 & PS-ATB & 0.564 & RES-ATB & 0.121 & OWN-Habit & 0.088 & PS-Habit & 0.87 & - & - \\
\hline
\end{tabular}


consumers opinion concerning the outsourcing of responsibility, consumers familiarity with paying for a service every time it is used and habits concerning the handing in of products after use (Table 3$)$ (Intention $=0.564^{*}($ PS-ATB $)+0.121^{*}($ RES ATB $+0.088^{*}(\mathrm{OWN}-$ Habit $\left.)+0.087^{*}(\mathrm{PS}-\mathrm{HABIT})\right)$. Together, these parameters explain 39.5 percent of the observed variance.

\section{Conclusion}

This paper aimed to investigate the role of consumers in the Circular Economy by using an extended version of the Theory of Planned Behaviour to test consumer intention towards Circular Business Model characteristics. The central question is to what extent product ownership, product responsibility and payment structure does affect consumer intention to participate in Circular Business Models which incorporate product take-back.

When comparing the intention to participate in the different CBMs, we observed that consumers appreciate take-back management considerably more than the other CBMs. Take-back management is assumed to be the most attractive CBM type for consumers at present (Table 7), and most probable to lead to behavioural change (Ajzen, 2011). Take-back management is thus the most suited CBM to facilitate product take-back initiatives, within the current scope and for the current electronics market.

The results clearly show the profound and reoccurring impact of payment structure as a business model characteristic influencing intention. The way consumers pay within a business model is seemingly of major importance to consumers when dealing with CBMs. As seen in all models, payment structure is invariably linked to attitude towards a behaviour and habit, which are in turn the most influential and reoccurring factors influencing intention according to the constructed multiple regressions. It can be concluded that additional focus should be spent on the need to ensure consumers have a positive opinion regarding the payment structure of a CBM. Companies need to find better ways to clarify the unburdening benefits of innovative service-oriented CBMs. The survey respondents indicated that the payment structure should incorporate an one-time transaction and a return scheme. This preference aligns well with the habits of the research population. This suggests that through investigating habits, companies can identify how customer segments would react to CBM types. Great potential lies in the further adjustment of CBMs to play into institutionalised habits thereby helping consumers to adjust to more CBMs in a gradual way. For example, the Dutch consumer is familiar with take-back schemes, for household waste, bottles or electronics which may explain their preference for this CBM type. If this research was repeated in other countries, different habits may suggest another CBM type as a starting point for widespread consumer acceptance.

Another main finding of this research regards the impact of responsibility which turned out to be the second most influential characteristic determining intention. Responsibility is of influence in all models, meaning that the in- or outsourcing of product responsibility by consumers is deemed important.

A final remarkable finding is that the third main CBM characteristic, ownership, was found to be neither strongly present nor influential in the consumers' decision-making process. Only in take-back management it seems to matter to a small extent who owns the product during and after-use. As ownership is weakly represented over the different measured models and has no impactful parameters listed in the determination of intention, it can be concluded that ownership is the least impactful characteristic in CBMs dealing with take-back schemes in the current electronics market. Accordingly, this industry has potential for implementing successful CBMs based on access to products and services rather than ownership. Conversely, research could investigate if this also applies to other types of goods such as consumption products with a relatively short lifecycle. This can potentially increase the successrate of service-oriented CBMs in numerous markets (Windahl and Lakemond, 2010; Mlecnik et al., 2012; Kyrousi et al., 2015).

\section{Discussion}

\subsection{Evaluation of the enrichment of the TPB}

Our study aimed to extend the application of TPB towards measuring environmental-related behaviour by introducing habits and environmental attitude to the original framework of Ajzen (1985). Below we will discuss the usefulness of the two newly introduced factors.

Habit is the first newly introduced parameter to Ajzen's (1985) framework. The influence of habits is abundantly present in all examined models as shown in the findings. In the Take-Back Management model, the habit-parameters are the strongest influencers. The habit-parameters are present, albeit less strong in the Lease and Pay-per-Print model. Additionally, the tolerance of the habit-parameters is very high, meaning the variance observed by these factors cannot be owned to other parameters in the model (Table 3). Therefore, habits increased the predictive value of the TPB to behaviour. This study acknowledges and supports the claim made by numerous scholars to include past behaviour, possibly in the form of habits, to the Theory of Planned Behaviour (Thøgersen, 1995; Stern, 2000; Hagger et al., 2002; Bamberg and Möser, 2007; Ajzen, 2011).

Environmental attitude is the second addition to the original Theory of Planned Behaviour framework. Compared to habit, EA is less strongly and frequently present in the researched models. While this parameter makes a significant contribution to the prediction of intention in TBM, with a high tolerance score, it is entirely absent in the remaining CBMs. This observation, however, does not indicate that EA cannot form a useful addition to the proposed framework. The observation of environmental attitude having a significant effect on intention in the Take-back Management model only, could be resulting from a specific perception and interpretation of the consumer. According to Minton and Rose (1997), consumers attitude towards the preservation of the environment is a strong contribution to intention. However, scholars like Thøgersen (1994), McCarty and Shrum (1994), Minton and Rose (1997), and Laroche et al. (2001), all address environmental attitude from a recycling perspective. These scholars claimed to have found a high measurement of consumers attitude to preserve the environment, while in fact they measured consumer attitude towards recycling. When adopting a consumer perspective, previous research described recycling as a method of separating and collecting used or waste products (Bom et al., 2017). Reflecting on the statement of Minton and Rose (1997), in combination with the found consumer definition of recycling, it can be concluded that consumer attitude towards the collection and separation of waste products, and not towards the preservation of the environment, is high.

The previous statement may explain the missing influence of EA in the product lease and pay-per-print models. In practice, takeback management makes use of collection points known to the consumer from other recycling initiatives. As stated, the practice of handing in used products is perceived as a pro-environmental behaviour resulting in environmental benefits. As can be seen in Table 6, consumers do not attribute environmental gains to the product lease and pay-per-print models, as they do not apply recycling schemes which are familiar to the consumer. Therefore, consumers do not perceive the environmental benefits of these CBMs, and do not weight environmental attitude as a relevant 
factor when determining intention towards the product lease and pay-per-print models. Business offering circular services should act upon this finding by highlighting the environmental benefits of service-based business models to increase consumer acceptance. Furthermore, it is important not to exclude EA from the TPB framework, as it can - when perceived relevant by the consumer significantly influence intention.

Future research should, when collecting data from the consumer, clearly differentiate between recycling and other environmentally-friendly behaviour. If so, differences in ATB, SN and habits concerning environmentally-friendly behaviour in general can be determined more accurately. Environmental education should shift away its focus from recycling, to increase awareness on other ways to preserve the environment in order to create more differentiated behaviour. Herewith, positive attitudes and habits can be formed which would increase familiarity with the unknown concepts of CBM and can lead to higher uptake of CBMs.

\subsubsection{Observed variance}

This study drafted three multiple regression models with the use of the extended version of the Theory of Planned Behaviour, based on real data, which accounted for 16.7, 27.3, and 39.5 percent of the observed variance. Relying on Cohen's (1988) standard, the first model is considered as relatively weak, whereas the remaining models fit the category strong.

A research by Armitage and Conner (2001) provides a possible explanation for these observed percentages; low variance score in the multiple regression models would mostly be due to a lack of a social norm. This study encountered similar results as scores measured for SN were moderate and non-influential over all models. An explanation could be the newness of the researched behaviour. This study investigated innovative Circular Business Model characteristics, with which society was yet unfamiliar. Due to the newness of these concepts and behaviours, social norms have not yet been established in society. Previous research noted a SN concerning environmental decision making is fluctuating and unpredictable (Russel et al., 2017). Therefore, using measurements from the current configuration of the SN within the TPB can be problematic.

\subsection{Limitations \& recommendations}

The current study includes some limitations which need to be addressed in further research. Within the current study, only few characteristics from the sample population are known. Apart from age and gender $(\operatorname{Avg}=60)$, no other socio-economical descriptors of the research population were known, as Canon is not legally permitted to collect such information. However, previous research has shown that personal factors, like gender and age, do not correlate significantly with a person's environmental engagement (Borden, 1985; De Leeuw et al., 2015). Moreover, Ajzen (1985) states such parameters would not have a direct effect on behaviour or intention in the Theory of Planned Behaviour. In order to confirm these claims, the research should be repeated with a research population in which other socio-economic factors can be addressed.

The results of this research indicate take-back management could be a successful strategy for companies to reclaim electronic products after use. Business actors could respond to the legal obligation while regaining valuable secondary materials.

The present study aimed to enrich the existing research on CBM consumer acceptance which lacks generalisable quantitative insights on preferential CBM design. Based on the current quantitative research design, generalised patterns can be detected which are valid across CBMs in the electronic sector and help to analyse diffusion and adoption of CBMs in various industries.

Finally, this study made the first attempt to map the consumers perspective towards Circular Business Models and identify the consumers beliefs associated with the practicalities accompanying a Circular Economy. These newly gained insights can be used by both scholars and businesses in the creation of new BMs. As this study clearly identified which characteristics are prioritised by the consumer, future research should address these characteristics specifically with more in-depth analysis.

\section{Author statement}

R. Elzinga: Conceptualization, Methodology, Validation, Formal analysis, Investigation, Data Curation, Writing - Original Draft, Writing - Review \& Editing, Visualization, Project administration.

D. Reike: Conceptualization, Validation, Writing - Review \& Editing, Visualization, Project administration.

S.0. Negro: Validation, Resources, Supervision, Project administration.

W.P.C. Boon: Conceptualization, Validation, Resources, Supervision, Project administration.

\section{Declaration of competing interest}

The authors declare that they have no known competing financial interests or personal relationships that could have appeared to influence the work reported in this paper.

\section{References}

Ajzen, I., 1985. From intentions to actions: a theory of planned behaviour. In: Action Control. Springer Berlin Heidelberg, pp. 11-39.

Ajzen, I., 1991. The theory of planned behavior. Organ. Behav. Hum. Decis. Process. 50 (2), 179-211.

Ajzen, I., 2006. Constructing a Theory of Planned Behavior Questionnaire.

Ajzen, I., 2011. The theory of planned behaviour: reactions and reflections. Psychol Health 26 (9), 1113-1127.

Ajzen, I., 2015. The theory of planned behaviour is alive and well, and not ready to retire: a commentary on Sniehotta, Presseau, and Araújo-Soares. Health Psychol. Rev. 9 (2), 131-137.

Armitage, C.J., Conner, M., 2001. Efficacy of the theory of planned behaviour: meta-analytic review. Br. J. Soc. Psychol. 40 (4), 471-499.

Awasthi, A.K., Cucchiella, F., D’Adamo, I., Li, J., Rosa, P., Terzi, S., Zeng, X., 2018 Modelling the correlations of e-waste quantity with economic increase. Sci. Total Environ. 613, 46-53.

Bagozzi, R.P., 1982. A field investigation of causal relations among cognitions, affect, intentions, and behaviour. J. Mark. Res. 19, 562-584.

Bagozzi, R.P., Dabholkar, P.A., 1994. Consumer recycling goals and their effect on decisions to recycle: a means-end chain analysis. Psychol. Mark. 11 (4), $313-340$.

Bamberg, S., Möser, G., 2007. Twenty years after Hines, Hungerford, and Tomera: a new meta-analysis of psycho-social determinants of pro-environmental behaviour. J. Environ. Psychol. 27 (1), 14-25.

Barquet, A.P.B., De Oliveira, M.G., Amigo, C.R., Cunha, V.P., Rozenfeld, H., 2013. Employing the business model concept to support the adoption of productservice systems (PSS). Ind. Mark. Manag. 42, 693-704.

Bocken, N.M.P., Short, S.W., Rana, P., Evans, S., 2014. A literature and practice review to develop sustainable business model archetypes. J. Clean. Prod. 65, 42-56.

Bom, U.B., Belbase, S., Bibriven Lila, R., 2017. Public perceptions and practices of solid waste recycling in the city of laramie in Wyoming, USA. Recycling 2 (3), 11.

Borden, R.J., 1985. Personality and ecological concern. In: Gray, D.B. (Ed.), Ecological Beliefs and Behaviors. Greenwood Press, Westport, CT, pp. 87-122.

Borrello, M., Caracciolo, F., Lombardi, A., Pascucci, S., Cembalo, L., 2017. Consumers' perspective on circular economy strategy for reducing food waste. Sustainability 9 (1), 141.

Bryman, A., 2015. Social Research Methods. Oxford university press.

Catulli, M., Cook, M., Potter, S., 2017. Consuming use orientated product service systems: a consumer culture theory perspective. J. Clean. Prod. 141, 1186-1193.

Cohen, J., 1988. Statistical Power Analysis for the Behavioral Sciences, 2nd.

De Leeuw, A., Valois, P., Ajzen, I., Schmidt, P., 2015. Using the theory of planned behaviour to identify key beliefs underlying pro-environmental behaviour in high-school students: implications for educational interventions. J. Environ. Psychol. 42, 128-138.

Ellen MacArthur Foundation, 2013. Towards the circular economy. J. Ind. Ecol. 2, 23-44. 
Ellen MacArthur Foundation, 2015. Delivering the Circular Economy, a Toolkit for Policymakers. Ellen MacArthur Foundation, Cowes, UK.

Fishbein, M., Ajzen, I., 1975. Beliefs, Attitude, Intention, and Behavior. AddisonWesley, Reading, MA.

Fishbein, M., Ajzen, I., 2010. Predicting and Changing Behaviour: the Reasoned Action Approach. Psychology Press, New York, NY.

Gardner, B., de Bruijn, G.J., Lally, P., 2011. A systematic review and meta-analysis of applications of the self-report habit index to nutrition and physical activity behaviours. Ann. Behav. Med. 42, 174-187.

Gatersleben, B., 2011. In: Lucas, Karen, Blumenberg, Evelyn, Weinberger, Rachel (Eds.), The Car as a Material Possession: Exploring the Link between Materialism and Car Ownership and Use. Auto Motives, pp. 137-148.

Geissdoerfer, M., Savaget, P., Bocken, N.M.P., Hultink, E.J., 2017. The Circular Economy - a new sustainability paradigm? J. Clean. Prod. 143, 757-768. https:// doi.org/10.1016/j.jclepro.2016.12.048.

Ghisellini, P., Cialani, C., Ulgiati, S., 2016. A review on circular economy: the expected transition to a balanced interplay of environmental and economic systems. J. Clean. Prod. 114, 11-32.

Guide, V.D.R., Harrison, T.P., van Wassenhove, L.N., 2003. The challenge of closedloop supply chains. Interfaces 33 (6), 3-6.

Hagger, M.S., Chatzisarantis, N.L., Biddle, S.J., 2002. A meta-analytic review of the theories of reasoned action and planned behavior in physical activity: predictive validity and the contribution of additional variables. J. Sport Exerc. Psychol. 24 (1), 3-32.

Harich, J., 2010. Change resistance as the crux of the environmental sustainability problem. Syst. Dyn. Rev. 26 (1), 35-72.

Kirchherr, J., Reike, D., Hekkert, M., 2017. Conceptualizing the circular economy: an analysis of 114 definitions. Resour. Conserv. Recycl. 127, 221-232.

Klöckner, C.A., 2013. A comprehensive model of the psychology of environmental behaviour-a meta-analysis. Glob. Environ. Chang. 23 (5), 1028-1038.

Kok, G., Siero, S., 1985. Tin recycling: awareness, comprehension, attitude, intention and behavior. J. Econ. Psychol. 6, 157-173.

Kyrousi, A.G., Koronaki, E., Theodoridis, P.K., 2015. Reaching for the better me: development of a scale to measure luxury consumer-Personal identity enrichment. In: Global Fashion Management Conference at Florence, 192-192.

Laroche, M., Bergeron, J., Barbaro-Forleo, G., 2001. Targeting consumers who are willing to pay more for environmentally friendly products. J. Consum. Mark. 18 (6), 503-520.

Lewandowski, M., 2016. Designing the business models for circular economy - towards the conceptual framework. Sustainability 8 (1), 43

Lu, C., Zhang, L., Zhong, Y., Ren, W., Tobias, M., Mu, Z., Xue, B., 2015. An overview of e-waste management in China. J. Mater. Cycles Waste Manag. 17 (1), 1-12.

Lüdeke-Freund, F., 2010. Towards a conceptual framework of business models for sustainability. In: Knowledge Collaboration \& Learning for Sustainable Innovation, Proceedings of the ERSCP-EMSU Conference (Delft, The Netherlands).

McCarty, J.A., Shrum, L.J., 1994. The recycling of solid wastes: personal values, value orientations, and attitudes about recycling as antecedents of recycling behavior. J. Bus. Res. 30 (1), 53-62.

Michelini, G., Moraes, R.N., Cunha, R.N., Costa, J.M., Ometto, A.R., 2017. From linear to circular economy: PSS conducting the transition. Procedia CIRP 64, 2-6.

Minton, A.P., Rose, R.L., 1997. The effects of environmental concern on environmentally friendly consumer behavior: an exploratory study. J. Bus. Res. 40 (1), 37-48.

Mlecnik, E., Kondratenko, I., Haavik, T., 2012. Business model development for customer-oriented housing renovation. In: Holistic Renovation. A3. 1.

Murray, A., Skene, K., Haynes, K., 2017. The circular economy: an interdisciplinary exploration of the concept and application in a global context. J. Bus. Ethics 140, 369-380.

Osterwalder, A., Pigneur, Y., 2010. Business Model Generation: a Handbook for Visionaries, Game Changers, and Challengers. John Wiley \& Sons.

Ouellette, J.A., Wood, W., 1998. Habit and intention in everyday life. Psychol. Bull. 124 (1), 54-74.

Pieters, R.G.M., 1991. Changing garbage disposal patterns of consumers: motivation, ability, and performance. J. Public Policy Mark. 10, 59-76.

Planing, P., 2018. Towards a circular economy-how business model innovation will help to make the shift. Int. J. Bus. Glob. 20 (1), 71-83.

Ramani, K., Ramanujan, D., Bernstein, W.Z., Zhao, F., Sutherland, J., Handwerker, C., et al., 2010. Integrated sustainable life cycle design: a review. J. Mech. Des. 132 (9), 091004.

Reike, D., Vermeulen, W.J.V., Witjes, S., 2018. The circular economy: new or Refurbished as CE 3.0? Resour. Conserv. Recycl. 135, 246-264.

Rexfelt, O., Hiort af Ornäs, V., 2009. Consumer acceptance of product-service systems: designing for relative advantages and uncertainty reductions. J. Manuf. Technol. Manag. 20 (5), 674-699.

Russell, S.V., Young, C.W., Unsworth, K.L., Robinson, C., 2017. Bringing habits and emotions into food waste behaviour. Resour. Conserv. Recycl. 125, 107-114.

Sheeran, P., 2002. Intention-behaviour relations: a conceptual and empirical review. Eur. Rev. Soc. Psychol. 121 (1), 1-36.

Sniehotta, F.F., Presseau, J., Araújo-Soares, V., 2014. Time to retire the theory of planned behaviour. Health Psychol. Rev. 8 (1), 1.

Stern, P.C., 2000. New environmental theories: toward a coherent theory of environmentally significant behaviour. J. Soc. Issues 56 (3), 407-424.

Thøgersen, J., 1994. A model of recycling behaviour, with evidence from Danish source separation programmes. Int. J. Res. Mark. 11 (2), 145-163.

Thøgersen, J., 1995. Understanding of consumer behaviour as a prerequisite for environmental protection. J. Consum. Policy 18 (4), 345-385.

Triandis, H.C., 1977. Interpersonal Behavior. Brooks/Cole Pub Co.

Tukker, A., 2004. Eight types of product-service system: eight ways to sustainability? Bus. Strateg. Environ. 13 (4), 246-260.

Tukker, A., 2015. Product services for a resource-efficient and circular economy-a review. J. Clean. Prod. 97 (1), 76-91.

Verplanken, B., Holland, R.W., 2002. Motivated decision making: effects of activation and self-centrality of values on choices and behavior. J. Personal. Soc. Psychol. 82 (3), 434.

Von Hippel, E., 2005. Democratizing innovation: the evolving phenomenon of user innovation. J. Betriebswirtschaft 55 (1), 63-78.

Webb, T.L., Sheeran, P., 2006. Does changing behavioural intentions engender behaviour change? A meta-analysis of the experimental evidence. Psychol. Bull. 132 (2), 249-268.

Windahl, C., Lakemond, N., 2010. Integrated solutions from a service-centered perspective: applicability and limitations in the capital goods industry. Ind. Mark. Manag. 39 (8), 1278-1290. 